\title{
Critical evaluation of the microbial turnover to biomass approach for the estimation of biogenic non-extractable residues (NER)
}

\author{
Stefan Trapp², Andreas Libonati Brock ${ }^{2}$, Matthias Kästner ${ }^{1 *} \mathbb{B}$, Andreas Schäffer ${ }^{3}$ (ID and Dieter Hennecke ${ }^{4}$
}

\begin{abstract}
Background: Persistence is a key criterion for the risk assessment of chemicals. In degradation tests, microbial biodegradation of labeled test chemicals leads to the incorporation of the label in microbial biomass, resulting in biogenic non-extractable residues (bioNER), which are not considered as harmful in persistence assessment. The amount of bioNER can be estimated using the microbial turnover to biomass (MTB) model. MTB estimates the biomass growth during productive degradation of a compound from theoretical growth yield and $\mathrm{CO}_{2}$-formation and gives an upper and a lower value for bioNER formation. The aim of this study is use available experimental data for bioNER to assess the validity, accuracy and precision of the MTB method as new tool in persistence assessment.

Results: We collected experimental data in order to test accuracy and precision of this estimation method. In total, 16 experimental studies were found in literature where bioNER was experimentally quantified. Hereof, 13 studies used the amount of label recovered from total amino acid (tAA) content as proxy for bioNER. Unfortunately, the comparison with experimental data was difficult due to the variety of employed methods. A conversion factor is required to extrapolate from tAA on bioNER, and this factor may vary during the experiment and between experiments. The bioNER formation for all compounds tested was calculated with the MTB method, and the outcome was compared to measured tAA as proxy for bioNER. The relation between predicted and measured bioNER was significant, but no better correlation was obtained than with $\mathrm{CO}_{2}$ to tAA. The mean absolute error of the prediction (low MTB versus tAA) was $5 \%$ applied label (range 0.3 to 16\%). Some deviation between measured results and calculated bioNER could be contributed to uncertainties in the experimental determination, as shown by variance in replicates (bromoxynil) or high background of label in sterile samples (sulfadiazine).
\end{abstract}

Conclusions: MTB thus provides a robust model for determining of the potential amounts of biomass and bioNER formed from the degradation of organic chemicals.

Keywords: Persistence assessment, Biodegradation, REACH, Bound residues

\section{Introduction}

Persistence is a key criterion in chemical risk assessment, and high persistence of any substance is of major concern [1, 2]. In chemical regulation, persistence is assessed in environmental simulation tests according

\footnotetext{
*Correspondence: matthias.kaestner@ufz.de

1 Department Environmental Biotechnology, Helmholtz Centre

for Environmental Research, UFZ, 04318 Leipzig, Germany

Full list of author information is available at the end of the article
}

to OECD guidelines, e.g., OECD biodegradation tests for soil (OECD TG 307), water and sediment (OECD TG 308), or for aerobic transformation in surface water with suspended sediment (OECD TG 309) [3-5]. Studies are commonly made with radioactive ${ }^{14} \mathrm{C}$-labeled compounds to detect unknown transformation products and metabolites. Nevertheless, in most if not all degradation studies of pesticides, only a part of the initially applied radiolabel can be extracted, and often non-extractable residues (NER) of the label remain in the matrix in 
significant amounts. In soil, up to $90 \%$ of the applied radioactivity may remain as non-extractable in the soil matrix [6]. The problem of NER occurs not only for pesticides, but is also a critical issue in the general persistence assessment of chemicals under REACH [7], hence the question arose "Is NER formation a safe sink or should it be considered as a hidden hazard?" [8].

For decades, non-extractable residues have been considered a "black box" of unknown chemical identity. Due to their non-extractability, the nature of NER has been almost impossible to characterize. Recent scientific progress with stable isotope labels showed that NER is not one single product, but is composed of fractions of quite different hazard potentials [9]. The scientific state-of-theart about NER was summarized in a discussion paper prepared for the European Chemicals Agency (ECHA) [10]. Accordingly, NER is classified into three types: NER type I are strongly sorbed, entrapped and/or sequestered parent substance or early transformation and degradation products, with release potential $[10,11]$; NER type II are covalently bound transformation and degradation products, considered to be slowly released, if at all; NER type III are biogenic NER, i.e., derived from living or dead biomass (bioNER) for soil organic matter formed from this necromass, with no hazard potential [9]. This biogenic NER or bioNER can thus be considered as a 'safe sink'

ECHA recently has changed paradigm and switched to a more conservative view on NER. Thus, in the recent updates of the ECHA REACH Guidance documents on chemical risk assessment $[12,13]$ and PBT assessment [14], NER are considered as derived from parent substances and as bioavailable, if no other data are showing evidence for degradation or irreversible binding. For existing studies, a recent note released by ECHA [7] states that "by default NER should be regarded as non-degraded".

NER can be characterized and differentiated between remobilizable (therefore still of potential concern) and irreversibly bound fractions, hence of low or no concern [7]. The characterization of NER succeeds by different extraction steps [11]. However, biogenic NER can also be calculated from microbial yield and $\mathrm{CO}_{2}$-evolution with the MTB ("Microbial turnover to biomass") method [15]. The theoretical yield can be calculated from thermodynamic (Gibbs energy of formation and reaction) and structural data, hence, does not require additional experimental input data. If total NER (type I, II, and III) have been measured and bioNER (type III) has been calculated, the amount of potentially hazardous "xenoNER" (type I and II) can be estimated from the difference. Moreover, yields calculated with the MTB method can also serve as input to dynamic simulation models for metabolism and growth of microbes in biodegradation tests, reducing the number of unknown input parameters and hence also the uncertainty of the model predictions [16]. Several growth-yield estimation methods were developed for various purposes [17-21]. The thermodynamic electron equivalent model (TEEM2) developed by McCarty [20], the expanded thermodynamic true yield prediction model (ETTYM) of Xiao and VanBriesen [21], and the microbial turnover to biomass (MTB) [15] were previously tested and compared by [22] for the accuracy to predict the yield from degradation of xenobiotics, with slight advantages for the latter.

Recently, the microbial growth yields of 40 organic chemicals of environmental concern (hereof 31 pesticides) were estimated [22]. The results were compared to experimental values and the results of other methods for yield assessment that are available in the literature. The MTB method performed best for xenobiotics and pesticides. The MTB bioNER estimation method is rather new, and few validation data have been available at the time of publication. Kästner et al. [10] therefore only recommended MTB as a screening approach, but did not consider it "as definitive proof for bioNER formation", due to the little experience gained with this method. However, "once sufficient (positive) experimental data have been gained it may be possible to rely on the calculated bioNER alone". The ECHA considers the MTB method as a helpful tool for the interpretation of degradation data, "in particular for existing cases, where information on NER types is usually not available. The likelihood of NER being biogenic (bioNER) or not could be very useful in the interpretation of the results" [7]. On the virtual workshop Proposal to standardize the analysis and persistence assessment of non-extractable residues (NER) 17-18 February 2021 on behalf of the German Environment Agency (Umweltbundesamt Dessau-Roßlau, Germany), the question was raised whether MTB estimates alone can serve for the interpretation of degradation data and for decisions about persistence of substances. Hence, this prospective bioNER assessment method may be of practical relevance in chemical risk assessment, if its reliability is shown and documented.

Since the mentioned methods for NER characterization have been published [10,11], new experimental data on NER characterization has appeared. In this study, we collected available experimental data for bioNER from literature, calculated the theoretical bioNER formation with the MTB tool, and confront the calculated results to the measured outcome. The goal is to test the bioNER estimation method, to critically evaluate the results in comparison to experimental data, and to conclude about validity, accuracy and precision of the MTB method as new tool in persistence assessment. 


\section{Methods}

\section{Microbial turnover to biomass estimation method} for microbial yield and bioNER formation

Microbial turnover to biomass (MTB) approach. The MTB method is based on the relation between released $\mathrm{CO}_{2}$ (as indicator of microbial activity and mineralization), microbial growth yield, and bioNER formation [15]. The growth yield, $Y$, is defined as the amount of biomass, $X$, (in g biomass, or in g labeled $\mathrm{C}$ ) formed from the mineralized substrate, $S$, (in g substrate, or in g labeled C):

$$
Y=\frac{\mathrm{d} X}{\mathrm{~d} S} .
$$

The microbial growth yield is defined as the mass of microbial biomass formed per mass of substrate consumed (g cells per g substrate, or g C per g C) [23]. Both measured and estimated microbial yields can be applied in these equations, but very few measured data of xenobiotics can be found [22]. The MTB method is based on the method provided by [18], with the main modification that only electron transfers from $\mathrm{C}-\mathrm{H}$ bonds can be used by microbes to gain catabolic energy [15]. The yield may be limited by the available energy and by the carbon from a compound.

Once the growth yield is known, the formation of bioNER is estimated from the carbon balance. When the substrate is mineralized, the carbon of the substrate forms either biomass (anabolism) or $\mathrm{CO}_{2}$ (catabolism). Thus, if the unit $\mathrm{g}$ labeled $\mathrm{C}$ is used, the ratio of microbial biomass, $X$, to $\mathrm{CO}_{2}$ is

$$
\text { high } \mathrm{MTB}=X_{\mathrm{bioNER}}=\frac{Y}{(1-Y)}\left[\mathrm{CO}_{2}\right]
$$

Labeled $\mathrm{C}$ fixed in biomass is considered bioNER, hence this relation gives the upper amount of labeled C turning into bioNER, named "high MTB" or $X_{\text {bioNER }}$. Microorganisms decay, and during longer experiments, microbial necromass is digested in the microbial food web, under formation of non-living soil organic matter (SOM), new microbial biomass and more $\mathrm{CO}_{2}$ [15]. Empirical data indicate that in long-term experiments, about $40 \%$ of the labeled carbon in biomass (mainly the protein fraction) turns into SOM, 10\% remains within living biomass and $\mathrm{f}=50 \%$ forms $\mathrm{CO}_{2}$ [24], formalized (all units: g labeled C):

$$
\text { low } \mathrm{MTB}=\frac{f \times Y}{(1-Y)+(1-f) \times Y} \times\left[\mathrm{CO}_{2}\right],
$$

where "low MTB" stands for the lower limit of bioNER formed. The calculations thus give an upper value (high MTB) representing living biomass, and a lower value (low MTB) representing the outcome of label turnover in the microbial food web.

\section{Experimental data from literature}

The scientific literature was screened for experimental bioNER data determined in OECD 307 (soil), 308 (sediment) or 309 (surface water) degradation studies [2-4]. The experimental results stem from a variety of sources and the reported bioNER data were quantified by various methods. Table 1 shows references to the collected studies and the methods employed. Most studies were made with soil as medium, one study was done with sediment. Various types of soil were used, and occasionally, amendments such as compost or litter were added [25, 26]. Both results for radiolabeled substances $\left({ }^{14} \mathrm{C}\right)$ and from stable isotopes labels $\left({ }^{13} \mathrm{C}\right)$ were found. The initially applied amount of test substance was in average 10 times higher with the stable isotope ${ }^{13} \mathrm{C}$ than with ${ }^{14} \mathrm{C}$ tests, which is due to the much higher natural ${ }^{13} \mathrm{C}$ background and is thus conflicting with OECD test guidelines (OECD 307). Aside from inhomogeneity of the test method, also a variety of test durations can be observed, ranging from 28 to 400 days. Hence, few studies were strictly following OECD 307 test guidelines, which would require maximum $120 \mathrm{~d}$ duration for the soil degradation test.

The majority of studies employed acidic extraction of NER by $6 \mathrm{M} \mathrm{HCl}$ with subsequent determination of selected amino acids (AA) and calculation of total amino acids (tAA) from the typical composition of microbial biomass (Table 1) as proxy for bioNER. Two studies, Cao et al. [27] and Luks et al. [26], measured total NER and, by silylation, the fraction of NER I and II. NER III (bioNER) was then calculated as bioNER = total NER NER I - NER II. Since there may be bioNER among the radioactivity that remains bound in the solid matrix after the silylation process which is hereby included as NER II, this method likely underestimates the true bioNER [10]. Zhu et al. [28] measured "apparent NER" by hydrolysis of soil samples with trifluoroacetic acid and named the released fraction bioNER. Additional data were provided by a research project funded by the German Environment Agency, [29]). Within this project, tAA hydrolyzed from proteins were analyzed as proxies for microbial biomass in the extracted soil fraction. The analysis was performed by acidic hydrolysis with subsequent purification in accordance with [30]. Major deviation was the direct analysis by radio-thin-layer chromatography (radio-TLC) without derivatization that is required for subsequent high-resolution-gas chromatography-mass spectroscopy (HR-GC-MS) analysis. In addition, the pre-cleaned extract termed "amino acid extract (AAE)" was used instead of individual amino acids as an easy to measure proxy for the tAA content (for details see [29]). 
Table 1 Studies of various compounds with experimental bioNER quantification found in literature

\begin{tabular}{|c|c|c|c|c|c|c|}
\hline Substance & $\begin{array}{l}\text { Incubation } \\
\text { time (days) }\end{array}$ & Label & Test & Method & Comment & References \\
\hline 2,4-D & 64 & ${ }^{13} \mathrm{C}$ & Soil & tAA & & {$[15,30,31]$} \\
\hline Ibuprofen & 90 & ${ }^{13} \mathrm{C}$ & Soil & tAA & & {$[15,30,31]$} \\
\hline Glyphosate & 80 & ${ }^{13} \mathrm{C},{ }^{15} \mathrm{~N}$ & Sediment & tAA & Co-label $\mathrm{C}$ and $\mathrm{N}$ & {$[16,32]$} \\
\hline Bisphenol S & 28 & ${ }^{14} \mathrm{C}$ & Soil & Silylation & bioNER calculated from measured NER I and II & [27] \\
\hline DP & 84 & ${ }^{14} \mathrm{C}$ & Soil & tAA & $\mathrm{C}_{\text {init }} 1 \mathrm{mg} / \mathrm{kg}$ & [33] \\
\hline DS & 84 & ${ }^{14} \mathrm{C}$ & Soil & tAA & Same & [33] \\
\hline \multirow[t]{2}{*}{ DA } & 84 & 14 & Soil & tAA & Same & {$[33]$} \\
\hline & & C & & & & \\
\hline Bromoxynil & 120 & ${ }^{13} \mathrm{C}_{1}{ }^{14} \mathrm{C}$ & Soil & AAE & $\mathrm{C}_{\text {init }} 4 \mathrm{mg} / \mathrm{kg}{ }^{14} \mathrm{C}, 40 \mathrm{mg} / \mathrm{kg}^{13} \mathrm{C}$ & [29] \\
\hline Bromoxynil & 32 & ${ }^{13} \mathrm{C}$ & Soil & tAA & $\mathrm{C}_{\text {init }} 50 \mathrm{mg} / \mathrm{kg}$ & [33] \\
\hline Bromoxynil & 56 & ${ }^{14} \mathrm{C}$ & Soil & tAA & $\mathrm{C}_{\text {init }} 16.5 \mathrm{mg} / \mathrm{kg}$ & {$[35]$} \\
\hline Isoproturon & 46 & ${ }^{14} \mathrm{C}$ & Soil & Unique & Unique method & {$[28]$} \\
\hline Isoproturon & 120 & ${ }^{13} \mathrm{C}_{1}{ }^{14} \mathrm{C}$ & Soil & $\mathrm{AAE}$ & $\mathrm{C}_{\text {init }} 4 \mathrm{mg} / \mathrm{kg}{ }^{14} \mathrm{C}$ and $40 \mathrm{mg} / \mathrm{kg}^{13} \mathrm{C}$ & {$[29]$} \\
\hline MCPA & 65 & ${ }^{13} \mathrm{C}$ & Soil & tAA & With/out litter & {$[25]$} \\
\hline Metamitron & 80 & ${ }^{13} \mathrm{C}$ & Soil & tAA & & [36] \\
\hline $\begin{array}{l}\text { Pendimethalin } \\
\text { (compost added) }\end{array}$ & 204,400 & ${ }^{14} \mathrm{C}$ & Soil & Silylation & bioNER calculated from measured NER I and II & [26] \\
\hline Sulfadiazine & 121 & ${ }^{13} \mathrm{C}_{1}{ }^{14} \mathrm{C}$ & Soil & AAE & $\mathrm{C}_{\text {init }} 4 \mathrm{mg} / \mathrm{kg}{ }^{14} \mathrm{C}$ and $40 \mathrm{mg} / \mathrm{kg}^{13} \mathrm{C}$ & [29] \\
\hline Substance no. 4 & 120 & ${ }^{14} \mathrm{C}$ & Soil & AAE & $\mathrm{C}_{\text {init }} 1 \mathrm{mg} / \mathrm{kg}$ & {$[37]$} \\
\hline
\end{tabular}

DP is dodecylphenol, DA is dodecylbenzyl trimethylammonium chloride, DS is dodecylbenzene sulfonic acid

"AAE" means amino acid extraction by $6 \mathrm{M} \mathrm{HCl}$ and subsequent clean-up by cation exchange SPE-Dowex column; tAA (total amino acid) determination was by $6 \mathrm{M} \mathrm{HCl}$ for protein extraction and subsequent determination of selected amino acids

\section{Detailed data available for three chemicals}

In addition to the literature data, three chemicals with varying potential for NER formation, namely bromoxynil, isoproturon and sulfadiazine, were selected and experiments with ${ }^{14} \mathrm{C}$-labels (and ${ }^{13} \mathrm{C}$-labels, not shown) have been performed and the detailed, time-continuous data are available [29]. A short background of these three chemicals is provided in the following.

Bromoxynil (3,5-dibromo-4-hydroxybenzonitrile, CAS no. 1689-84-5) is a widely applied nitrile herbicide, which forms both bioNER and xenoNER $[34,35]$.

Sulfadiazine (4-amino-(N-pyrimidin-2-yl)benzenesulfonamide, CAS no. 68-35-9) is a sulfonamide antibiotic, commonly used both in humans and in livestock. It is not readily metabolized in humans nor in animals and is introduced onto agricultural fields with livestock manure and/or wastewater sludge. It has a low tendency to be biodegraded and as such is not expected to lead to the formation of considerable amounts of bioNER, instead, it is expected to form high amounts of NER type I and II [38]. Fast dissipation of sulfadiazine was found in Chen et al. [39], however, without quantification of mineralization.

Isoproturon (3-(4-isopropylphenyl)-1,1-dimethylurea, CAS no. 34123-59-6) is a phenylurea herbicide. The herbicide is banned in the European Union due to the toxicity of its metabolites and endocrine disrupting properties, it is however still detected in the environment. A recent study showed that isoproturon has a high tendency to form bioNER if the soil is inoculated with an isoproturon-degrading community [28].

\section{Chemical input data for the MTB method}

The estimation of microbial growth yields with the MTB method requires as input: (i) the balanced chemical reaction; (ii) Gibbs energy of formation of products and educts $\left(\Delta G_{f}\right)$; (iii) the molar mass $\mathrm{M}$; (iv) the number of carbon atoms in the molecule; and (v) the number of $\mathrm{C}-\mathrm{H}$ bonds.

Unless indicated otherwise, the reaction is always assumed to occur under aerobic conditions, with oxygen $\mathrm{O}_{2}$ as electron acceptor and $\mathrm{CO}_{2}$ and $\mathrm{H}_{2} \mathrm{O}$ as products. Nitrogen and sulfur moieties are assumed to keep the oxidation status they had in the substrate (e.g., amines are released as $\mathrm{NH}_{3}$ ).

Gibbs energies of formation $\left(\Delta G_{f}^{0}\right)$ for xenobiotics are rarely measured, and the values were estimated by the Weizmann equilibrator [40]. If the target compound was not listed, the value for a structurally similar compound was taken. Usually, the Gibbs energy of the educt contains far less energy than that of the products (mostly $\mathrm{CO}_{2}$ and $\mathrm{H}_{2} \mathrm{O}$ ), it is thus not a sensitive input data, and 
omitting the $\Delta G_{\mathrm{f}}^{0}$ value (setting it equal to $0 \mathrm{~kJ} \mathrm{~mol}^{-1}$ ) of the xenobiotic compound does in most cases not lead to more than $5 \%$ error [22]. For the products, measured $\Delta G_{\mathrm{f}}^{0}$ values were chosen where available $[18,22]$. The values for the Gibbs energy $\Delta G_{\mathrm{f}}^{0}$ were taken for standard conditions ( $\mathrm{pH} 0$ and $I=1 \mathrm{M}$ ). Values for other conditions (e.g., $\mathrm{pH} 7$ and $\mathrm{I}=0.01 \mathrm{M}$, physiological conditions) can be chosen, but the resulting Gibbs energy of the reaction $\left(\Delta G_{\mathrm{r}}\right)$ is almost identical ( $\leq 2 \%$ difference, tested for bromoxynil, isoproturon and sulfadiazine), provided the same conditions are chosen for all reaction partners and $\mathrm{H}^{+}$is corrected for $\mathrm{pH}$. Table 2 lists the postulated chemical reactions and the $\Delta G_{\mathrm{f}}^{0}$ for the compounds studied.

\section{Quality assessment}

The accuracy of the prediction method was assessed using the absolute error (AE) in the unit \% aL (applied label) which includes radio and stable isotope label:

$$
\mathrm{AE}_{i}(\% \mathrm{aL})=y-x,
$$

where $y$ is the predicted value (MTB-bioNER) and $x$ is the measured value. The mean absolute error (MAE) (\% $\mathrm{aL}$ ) is then

$$
\operatorname{MAE}(\% \mathrm{aL})=\frac{\sum_{i=1}^{n} \mathrm{AE}_{i}(\% \mathrm{aL})}{n},
$$

where $i=1, \ldots, n$ is the experimental data and $\mathrm{n}$ is the total number of data $(n=13)$.

The absolute error relative to the measured value $\mathrm{AE}_{i}(x)$ is defined by:

$$
\mathrm{AE}_{i}(x)=\frac{|y-x|}{x}
$$

The mean absolute error related to the measured value of $x \operatorname{MAE}(x)$ is then

$$
\operatorname{MAE}(x)=\frac{\sum_{i=1}^{n} \operatorname{AE}_{i}(x)}{n} .
$$

Moreover, the correlation $r$ and the coefficient of determination $r^{2}$ between estimated bioNER and measured tAA was calculated and plotted. All calculations were made in Microsoft Excel.

\section{Results}

Comparison of MTB-predicted bioNER to measured results

The calculated yields and the measured $\mathrm{CO}_{2}$-release used as input data to the MTB-bioNER estimation (Eqs. 2-3), the calculated high MTB-bioNER (Eq. 2), the low MTBbioNER (Eq. 3), and the measured label recovered from amino acids (total amino acids, tAA, in the unit $\% \mathrm{aL}$ ) are all shown in Table 3. In four studies, bioNER was determined by other methods, see Table 3 . The duration of the experiment is also given. If results for multiple sampling times were given, the experimental result from the sampling closest to 120 days is given.

Variation of measured $t A A$. The tAA of bromoxynil has been determined three times, each time with a different method, and the observed variance in replicate determinations is high: $\% \mathrm{aL}$ in tAA or AAE at the end of the experiment is $3.1 \%, 12 \%$ and $14.5 \%$. Similarly,

\begin{tabular}{|c|c|c|}
\hline Compound & $\Delta G_{\mathrm{f}}^{0} \mathrm{~kJ} / \mathrm{mol}$ & Reaction \\
\hline $2,4-D$ & -443.5 & $\mathrm{C}_{8} \mathrm{H}_{6} \mathrm{O}_{3} \mathrm{Cl}_{2}+7.5 \mathrm{O}_{2} \rightarrow 8 \mathrm{CO}_{2}(\mathrm{~g})+2 \mathrm{H}_{2} \mathrm{O}(\mathrm{I})+2 \mathrm{HCl}$ \\
\hline Ibuprofen & -184.0 & $\mathrm{C}_{13} \mathrm{H}_{18} \mathrm{O}_{2}+\mathrm{O}_{2} \rightarrow 13 \mathrm{CO}_{2}+9 \mathrm{H}_{2} \mathrm{O}$ \\
\hline Glyphosate & -1480 & $\mathrm{C}_{3} \mathrm{H}_{8} \mathrm{NO}_{5} \mathrm{P} \rightarrow 3 \mathrm{CO}_{2}$ \\
\hline Glyphosate $\rightarrow$ AMPA & -268 & $\mathrm{C}_{3} \mathrm{H}_{8} \mathrm{NO}_{5} \mathrm{P} \rightarrow \mathrm{CH}_{6} \mathrm{NO}_{3} \mathrm{P}+2 \mathrm{CO}_{2}$ \\
\hline Bisphenol S & -145.4 & $\mathrm{C}_{12} \mathrm{H}_{10} \mathrm{O}_{4} \mathrm{~S} \rightarrow 12 \mathrm{CO}_{2}+5 \mathrm{H}_{2} \mathrm{O}+(\mathrm{S}$ ignored $)$ \\
\hline Dodecylphenol & 1200 & $\mathrm{C}_{18} \mathrm{H}_{30} \mathrm{O} \rightarrow 18 \mathrm{CO}_{2}+15 \mathrm{H}_{2} \mathrm{O}$ \\
\hline DS, DA & & same yield taken as for dodecylphenol \\
\hline Bromoxynil & 147.8 & $\mathrm{C}_{7} \mathrm{H}_{3} \mathrm{Br}_{2} \mathrm{NO}+6 \mathrm{O}_{2}+\mathrm{OH}^{-} \rightarrow 7 \mathrm{CO}_{2}+2 \mathrm{Br}^{-}+\mathrm{NH}_{4}^{+}$ \\
\hline Isoproturon & 64.2 & $\mathrm{C}_{12} \mathrm{H}_{18} \mathrm{~N}_{2} \mathrm{O} \rightarrow 12 \mathrm{CO}_{2}+7.5 \mathrm{H}_{2} \mathrm{O}+2 \mathrm{NH}_{3}$ \\
\hline MCPA & -443.8 & $\mathrm{C}_{9} \mathrm{H}_{9} \mathrm{ClO}_{3} \rightarrow 9 \mathrm{CO}_{2}+4 \mathrm{H}_{2} \mathrm{O}+\mathrm{HCl}$ \\
\hline Metamitron & 414.8 & $\mathrm{C}_{10} \mathrm{H}_{10} \mathrm{~N}_{4} \mathrm{O} \rightarrow 10 \mathrm{CO}_{2}+3 \mathrm{NH}_{3}\left(\mathrm{NH}_{3}\right.$ disregarded $)$ \\
\hline Pendimethalin & 944.3 & $\mathrm{C}_{13} \mathrm{H}_{19} \mathrm{~N}_{3} \mathrm{O}_{4} \rightarrow 13 \mathrm{CO}_{2}+8 \mathrm{H}_{2} \mathrm{O}\left(+\mathrm{NH}_{3}+2 \mathrm{NO}_{2}\right.$ disregarded $)$ \\
\hline Sulfadiazine & 270.3 & $\mathrm{C}_{10} \mathrm{H}_{10} \mathrm{~N}_{4} \mathrm{O}_{2} \mathrm{~S}+2 \mathrm{H}_{2} \mathrm{O} \rightarrow 10 \mathrm{CO}_{2}+4 \mathrm{NH}_{3}+\mathrm{H}_{2} \mathrm{SO}_{4}$ \\
\hline
\end{tabular}
the measured bioNER of isoproturon by Zhu et al. [28] is far higher $(24.8 \%)$ than the \% aL in AAE derived by

Table 2 Postulated chemical reaction and the Gibbs energy for the studied compounds. $\mathrm{O}_{2}\left(\Delta G_{f}=0 \mathrm{~kJ}\right.$ mol $\left.{ }^{-1}\right)$ not shown

Assumptions: $\mathrm{N}$ and $\mathrm{S}$ keep the oxidation state they have in the parent molecule. In the $\Delta \mathrm{G}_{\mathrm{r}}$ of pendimethalin and metamitron, formation of $\mathrm{NH}_{3}$ and $\mathrm{NO}_{3}$ was disregarded in the calculation of $\Delta G^{0}$. Furthermore, it was assumed that in the unit $\mathrm{gC} / \mathrm{gC}$, DA is dodecylbenzyl trimethylammoniumchloride (DA) and dodecylbenzene sulfonic acid (DS) have the same yield as dodecylphenol, because the functional group is removed in the degradation chain. Glyphosate has two degradation pathways, one leading to complete mineralization, and one where AMPA is formed [16] 
Table 3 Measured and calculated bioNER

\begin{tabular}{|c|c|c|c|c|c|c|c|c|}
\hline Compound & $\begin{array}{l}\text { Incubation } \\
\text { time (days) }\end{array}$ & $\begin{array}{l}\mathrm{CO}_{2} \\
\% \mathrm{aL}\end{array}$ & $\begin{array}{l}\text { Yield } \\
\mathrm{gC} / \mathrm{gC}\end{array}$ & $\begin{array}{l}\text { low MTB } \\
\% \mathrm{aL}\end{array}$ & $\begin{array}{l}\text { high MTB } \\
\% \text { aL }\end{array}$ & $\begin{array}{l}\text { Meas. tAA } \\
\% \mathrm{aL}\end{array}$ & $\begin{array}{l}\text { Meas. bioNER } \\
\% a \mathrm{aL}\end{array}$ & References \\
\hline $2,4-D^{a}$ & 64 & 57.6 & 0.28 & 9.31 & 22.2 & 23.3 & & {$[15,31]$} \\
\hline Ibuprofen ${ }^{\mathrm{a}}$ & 90 & 45.2 & 0.43 & 12.4 & 34.1 & 28.4 & & {$[15,31]$} \\
\hline Glyphosate & 80 & 50.9 & 0.19 & 12.4 & 24.7 & $10.3^{e}$ & & {$[16]$} \\
\hline Dodecylphenol & 84 & 43.4 & 0.51 & 14.9 & 45.7 & 14.8 & & [33] \\
\hline DS & 84 & 67 & $0.51^{b}$ & 23.1 & 70.6 & 19.6 & & [33] \\
\hline DA & 84 & 24.2 & $0.51^{b}$ & 8.35 & 25.5 & 4.8 & & [33] \\
\hline Bromoxynil & 120 & 28.8 & 0.164 & 2.6 & 5.7 & $3.1^{f}$ & & [29] \\
\hline Bromoxynila $^{a}$ & 32 & 25 & 0.164 & 2.3 & 4.9 & 12 & & [34] \\
\hline Bromoxynil & 56 & 19 & 0.164 & 1.7 & 3.7 & 14.5 & & {$[35]$} \\
\hline Isoproturon & 120 & 17.0 & 0.46 & 5 & 14 & $5.3^{f}$ & & [29] \\
\hline Isoproturon & 46 & 55.9 & 0.46 & 16.4 & 46.5 & & 24.8 & [28] \\
\hline $\mathrm{MCPA}^{\mathrm{a}}$ & 70 & 4.3 & 0.35 & 0.89 & 2.26 & $1.2^{\mathrm{d}}$ & & [25] \\
\hline$M{ }^{2} A^{a}$ & 65 & 27 & 0.35 & 9.62 & 14.2 & & 13.8 & [25] \\
\hline Metamitron & 80 & 60 & 0.34 & 12.5 & 31.5 & 15.0 & & {$[36]$} \\
\hline Sulfadiazine & 121 & 1.7 & 0.36 & 0.4 & 0.9 & $7.0^{f}$ & & [29] \\
\hline Substance no. 4 & 120 & 63.4 & 0.27 & 9.9 & 23.5 & 5.5 & & {$[37]$} \\
\hline Bisphenol S & 28 & 53.6 & 0.30 & 8.9 & 21.7 & & 5.6 & [27] \\
\hline Pendimethalin & 204 & 11.1 & 0.50 & 3.8 & 11.4 & & $22^{c}$ & [26] \\
\hline
\end{tabular}

tAA is total amino acids; DA is dodecylbenzyl trimethylammoniumchloride, DS is dodecylbenzene sulfonic acid

${ }^{\text {a }}$ Experiment with ${ }^{13} \mathrm{C}$-label

${ }^{b}$ Same yield as dodecylphenol

' Sum of NER II and NER III

d Experiment "no litter" in Nowak et al. [25]

e tAA derived from ${ }^{13} \mathrm{C}$-label

$f_{\% a L}$ in $A A E$

Hennecke et al. [29] (5.3\% aL). Nowak et al. [25] found very different tAA of MCPA when litter was added as co-substrate. Without litter, a maximum of $1.2 \%$ of aL was recovered from tAA, and mineralization was low $\left(4.2 \% \mathrm{CO}_{2}\right)$. Addition of litter increased the mineralization $\left(27 \% \mathrm{CO}_{2}\right)$ and NER formation (21\%), hereof $13.8 \%$ bioNER. It can be concluded that the experimental conditions have a very decisive impact on the formation of tAA and bioNER. The only parameter in the MTB assessment that reflects experimental conditions is the $\mathrm{CO}_{2}$ release. Other relevant factors, such as initial degrader biomass, temperature, co-substrate and competing reactions (NER I and II formation) may also affect the outcome. This deserves further investigation.

Different methods to quantify $t A A$. For the determination of tAA, proteins in NER were extracted by $6 \mathrm{M} \mathrm{HCl}$, and the extract was cleaned up by a cation-exchange solid-phase extraction (SPE). In all studies, except those of Hennecke et al. [29], selected amino acids present in the extract were analyzed, and from the expected ratio of amino acids in microbiota the tAA was calculated [35]. Hennecke et al. [29] calculated the amino acid fraction directly from the radioactivity in the cleaned cation exchange eluate (AAE). Later, amino acids were determined for some samples, and the amount of radioactivity in amino acids (tAA) was somewhat lower than that in AAE [29]. Additionally, Claßen et al. [32] provided data for the comparison of the two methods, and in average, $\mathrm{AAE}$ was 1.37 times tAA, with a range between 0.51 to 2.6, while for substance No 4 [36] the ratio AAE/tAA was in average 1.43, ranging from 1.39 to 1.54 . However, these preliminary results stem from only two studies, and in the following statistical evaluation, no difference was made between the two methods.

\section{Statistical evaluation}

Correlation. Despite the high variance in experimental data, the correlation between measured tAA and MTB is significant both for the low MTB $(r=0.56)$ and the high MTB $(r=0.54)$ (with $n=14, r_{\text {crit }}$ is 0.53 at a level of significance, $\alpha=0.05$ ). A linear correlation matrix between both is shown in Table 4. There is no significant correlation between $\mathrm{CO}_{2}$ formation and yield $(r=0.07)$, but the correlation between $\mathrm{CO}_{2}$ and tAA is also significant $(r=0.55)$, while that of the yield to tAA is much lower ( $r=0.15$, not significant). Hence, it is 
Table 4 Pearson bivariate linear correlation coefficient $r$

\begin{tabular}{llllll}
\hline & tAA & $\mathbf{C O}_{2}$ & Yield & Low MTB & High MTB \\
\hline tAA & $*$ & & & & \\
$\mathrm{CO}_{2}$ & 0.58 & $*$ & & & \\
Yield & 0.15 & 0.07 & $*$ & & \\
Low MTB & 0.56 & 0.84 & 0.51 & $*$ & \\
High MTB & 0.54 & 0.75 & 0.62 & 0.98 & $*$ \\
Average MTB & 0.54 & 0.77 & 0.59 & 0.99 & 0.999 \\
\hline
\end{tabular}

For $\mathrm{n}$ is $14, \mathrm{r}_{\text {crit }}(5 \%$ significance level) is at 0.53 . tAA is total amino acids or amino acid extract; Yield is calculated from Eq. 1. Low MTB is calculated from Eq. 3; High MTB from Eq. 2; Average MTB is (low MTB + high MTB)/2

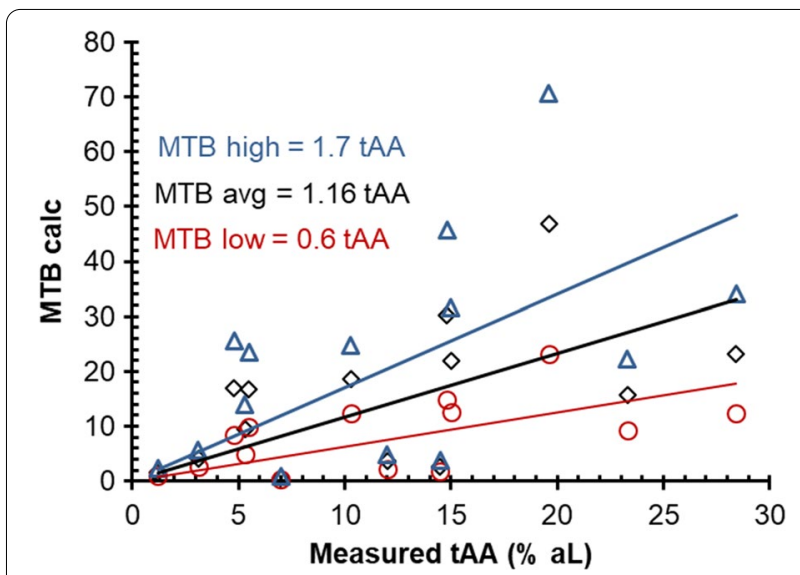

Fig. 1 Calculated bioNER (low, high, average MTB) versus measured tAA or AAE (unit \% applied label \%aL) for 14 substances listed in Tables 2 and 3. High MTB (Eq. 2, blue triangles and blue trendline); low MTB (Eq. 3, red circles and red trendline) and average MTB (= (low MTB + high MTB)/2) (black diamonds and black trendline)

the variation in $\mathrm{CO}_{2}$, which determines the variation of tAA. This makes sense as $\mathrm{CO}_{2}$ is the descriptor of the microbial activity, and for the given data set it varies far more (factor 39) than the yield (factor 3.1) (Table 3).

Plot of MTB-bioNER versus tAA. Figure 1 shows the plot of the measured tAA versus low, high and average MTB with the trend line forced through the origin and depicted slope. Living biomass consists of about $50 \%$ of amino acids [41], which might be the reason that high MTB (which predicts living biomass formed) has a slope of 1.7 to tAA. However, during turnover of biomass in the microbial food web, these other biomolecules are respired, while proteins and the amino acids therein are rather stable [24]. In long-term experiments, bioNER is approaching tAA (both living and dead tAA and proteinaceous material fixed in soil organic matter). The experiments were conducted over different time periods (from 32 to 121 days, Table 1), and it can be expected that the relation between tAA and bioNER in these experiments is between factor 1 and 2.

Mean absolute error. The low MTB has an absolute error in the prediction of tAA of, on average, $5.5 \% \mathrm{aL}$, high MTB 13.9\%aL, and average MTB 9.0\%aL. Low MTB has the smallest deviation from tAA because it is comparable to tAA, while high MTB is predicting living biomass, of which only $50 \%$ is amino acids.

\section{Calculated MTB-bioNER and measured \%aL in amino acid extract over time}

Due to the dynamic nature of the relation between bioNER and amino acids during a degradation experiment, the relation between measured AAE and predicted bioNER over time is shown for two substances [29].

The measured $\mathrm{AAE}$ and the $\mathrm{CO}_{2}$-release for the degradation study with ${ }^{14} \mathrm{C}$-isoproturon at five sampling events (7, 14, 29, 59 and 120 days) is shown in Fig. 2. The ratio of measured $\mathrm{CO}_{2}$ to $\mathrm{AAE}$ is continuously increasing over time, from 1.4 at day 7 to 3.2 at day 120 . This is consistent with the process of biomass turnover leading to upconcentration of amino acids and release of new $\mathrm{CO}_{2}$. In sterile samples, very little AAE was found $(\leq 0.4 \% \mathrm{aL})$. The calculated low MTB-bioNER is very close to the measured AAE for all five samples. In fact, the lower MTB predicts bioNER after the initial biomass has been degraded, and mostly amino acids remain (Eq. 3, [15]), thus represents a value close to the amino-acid content in bioNER. However, it is not possible that the initial bioNER consists only of amino acids-it is mostly living biomass, and thus contains more biomolecules than just proteins. Therefore, the high MTB (Eq. 2) should be a better descriptor for the living biomass formed from the productive microbial degradation of the compounds. Multiplying tAA (or AAE) by a factor 2 gives values above high MTB for all times except the last two samples at $t=59 \mathrm{~d}$ and $120 \mathrm{~d}$. Factor 1.8 gives values above but close to the high MTB until day 14, later on approaching the calculated low MTB.

Microbial biomass consists of about $50 \% \mathrm{w} / \mathrm{w}$ proteins [41], which justifies an initial factor 2 to calculate bioNER from tAA. The factor also depends on the composition of the amino acids ([16], SI). A typical half-live of microbes is 2 weeks $[15,42]$, and this means that after 120 days (the usual length of an OECD 307 degradation study) only $0.3 \%$ of the initial biomass would still be present. Only the degrader community takes up the label, and later those microbes that decompose decaying degrader cells. It depends thus on the lag phase, on the growth velocity of the degraders, and how much of their biomass is alive in the long run up to 120 days. When microbes decay, the bulk biomass is quickly metabolized in the microbial food web, whereupon $\mathrm{CO}_{2}$ and new biomass 


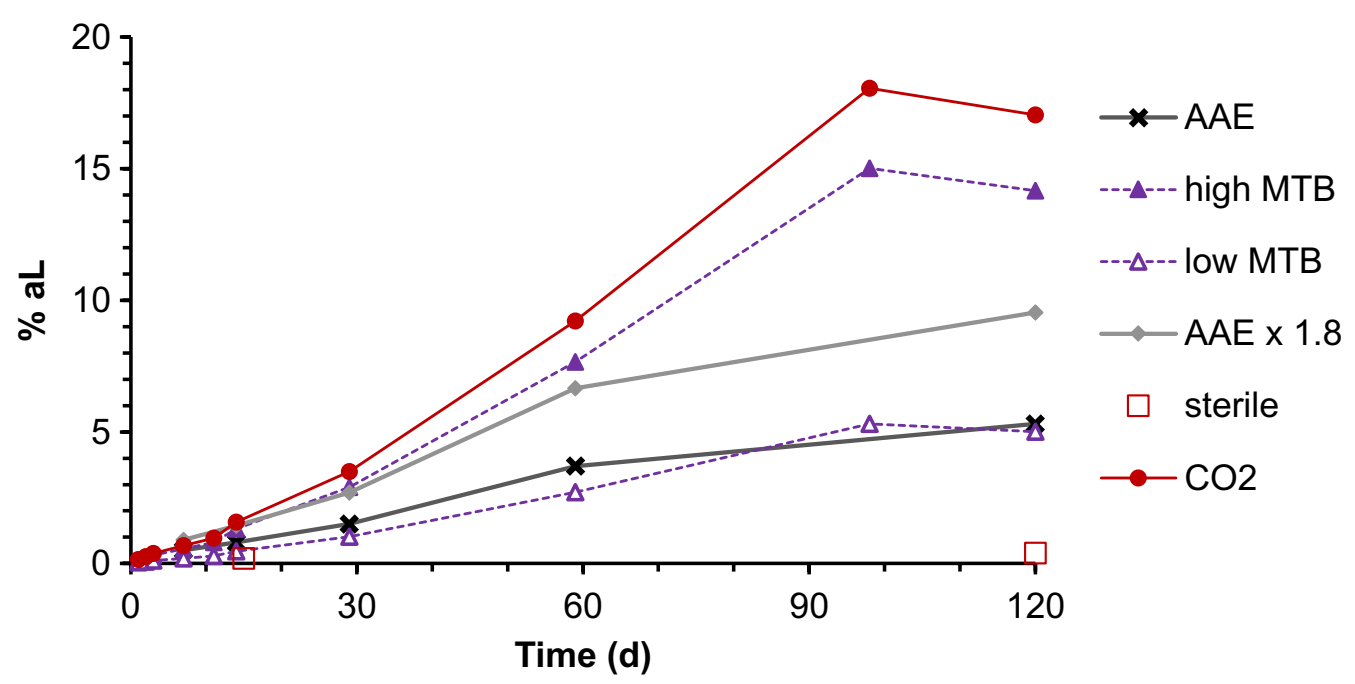

Fig. 2 Measured \%aL in cleaned-up column extract (AAE "amino acid extract", black line and crosses) and $\mathrm{CO}_{2}$ (\%aL, red circles and red dotted line), AAE in sterile samples (\%aL, red squares), AAE times factor $b=1.8$ (grey line and triangles), in comparison to low (dotted violet line and empty violet triangles) and high calculated MTB-bioNER (filled violet triangles and dashed violet line) for isoproturon at five consecutive sampling times (7, 14, 29, 59 and 120 days). Mean of replicate samples are shown $(n=2)$

forms (this is the reasoning behind Eq. 3) [43]. However, the most stable fraction of the biomass is the proteins, which remain often unchanged as soil organic matter (SOM) [24]. This is also why total amino acids are higher than amino acids from living organisms and are analyzed as a proxy for bioNER. However, the longer the test operates and the faster the initial degrader strains were growing, the less living biomass remains, until the label finally can dominantly be found in proteins (of biomass and in $\mathrm{SOM}$ ). It was thus postulated that the ratio bioNER to
tAA decreases from the maximum value 2 to lower ones and ultimately approaches 1 . Figure 2 shows AAE $\times 1.8$ (grey triangles), which ranged most of the time between low and high MTB and can thus be considered a "reasonable average factor on $\mathrm{tAA}$ to derive real bioNER for most of the time" in this isoproturon degradation experiment.

Figure 3 shows for bromoxynil the measured radiolabel $(\% \mathrm{aL})$ in the cleaned column extract (AAE), also in sterile samples, and measured $\mathrm{CO}_{2}$ at five consecutive sampling times $(7,14,27,62$ and 120 days). Already in

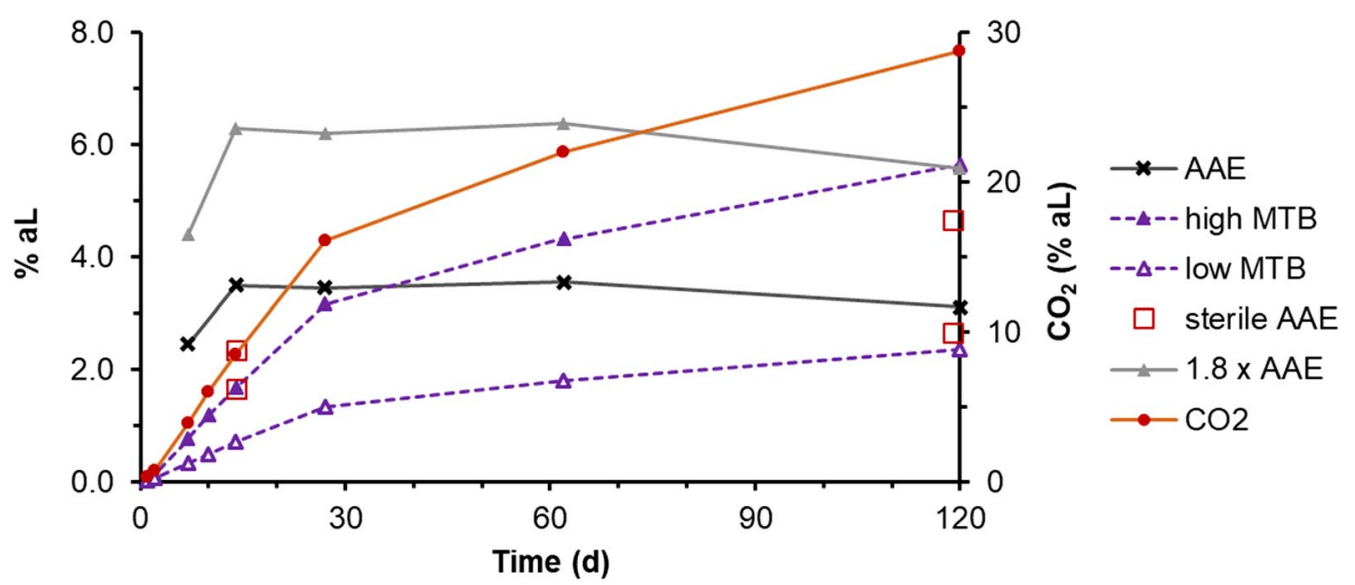

Fig. 3 Measured \%aL in cleaned-up column extract (AAE "amino acid extract", black line and crosses) and $\mathrm{CO}_{2}$ (\%aL right y-axis, red circles and red line), AAE in sterile samples (black diamonds), AAE times factor $b=1.8$ (grey line and triangles), in comparison to low (dotted violet line and empty violet triangles) and high calculated MTB-bioNER (filled violet triangles and dashed violet line) for bromoxynil at five consecutive sampling times ( 7 , $14,27,62$ and 120 days). Means of replicate samples are shown $(n=2)$ 
the first sample at $t=7$ days, measured AAE is rather high $(2.4 \%$ and $2.5 \%$ of $\mathrm{aL})$. In the second sample, $t=14$ days, $3.4 \%$ and $3.6 \% \mathrm{aL}$ were found in AAE. Also, in sterile controls a similar amount $(1.7 \%$ and $2.4 \% \mathrm{aL})$ is found in AAE. The label in AAE remains at this level over all sampling times, and is similar in sterile probes at $t=120$ days. This pattern is different from the measured $\mathrm{CO}_{2}$ and the calculated MTB-bioNER, which both increase with time. Thus, even though there is a good numerical agreement between calculated MTB-bioNER and measured AAE at $t=120 \mathrm{~d}$, and with measured AAE in between lower and higher MTB, there seems to be a disturbance of the measurement that leads to a high background, and that makes this result doubtful.

A similar pattern occurred for the compound sulfadiazine. Here, measured AAE was consistently high, up to $7.0 \% \mathrm{aL}$ at $t=120$ days, and also in sterile controls (3.6\% at $t=120$ days), despite very low $\mathrm{CO}_{2}$-development $(<2 \%$ at $t=120$ days $)$. The radioactivity recovered from AAE cannot be considered valid for bioNER (not shown).

For substance no. 4, measured radioactivity in the column extract $\mathrm{AAE}$ ) and in $\mathrm{CO}_{2}$ increase together (Fig. 4). Additionally, amino acids in the extract have been determined at three time points (14, 28 and $58 \mathrm{~d}$ ). Accordingly, between 65 and $72 \%$ of the label in the column extract is amino acids in this case. The low MTB-bioNER is close to the measured column extract. Multiplied with factor 1.8, the value is between low and high MTB, with the final value at $t=120$ days rather close to the low MTB.

\section{Discussion}

The MTB growth yield method has been tested earlier versus available data and also versus alternative growth yield estimation approaches [22]. MTB performed best for xenobiotics but still had a mean average error of $49 \%$ with both over- and underestimations; the high deviation was due to failure for a few substances, and the reasons for failure could be identified in more detail in this study by comparing mass balance data from various sources.

\section{Assumptions and limitations of the MTB growth yield and bioNER estimation}

Assumptions of the MTB method. The MTB yield calculation method is based on earlier work of Thauer et al. [23] and Diekert [18]. It gives the potential growth or the theoretical yield of microorganisms (pure strains or mixed cultures) on a defined substrate using it as sole source of carbon and energy. However, if the microorganisms grow on multiple substrates, as often seen at low substrate concentrations (starvation metabolism, sometimes mixed with the term co-metabolism) [44-46] and in soils or sediments, MTB still predicts the potential yield for a target substrate used for catabolism and anabolism in the same amount as in single substrate metabolism. However, if a substrate is preferably used for energy (ATP generation under $\mathrm{CO}_{2}$-release) and another carbon source, such as litter, is preferably utilized for biomass formation, the growth yield cannot be predicted reliably by this method if this carbon distribution is not known beforehand. The method assumes that catabolism and anabolism occur at the same time from the same substrate, which means that $\mathrm{CO}_{2}$ is formed and immediately released, while biomass

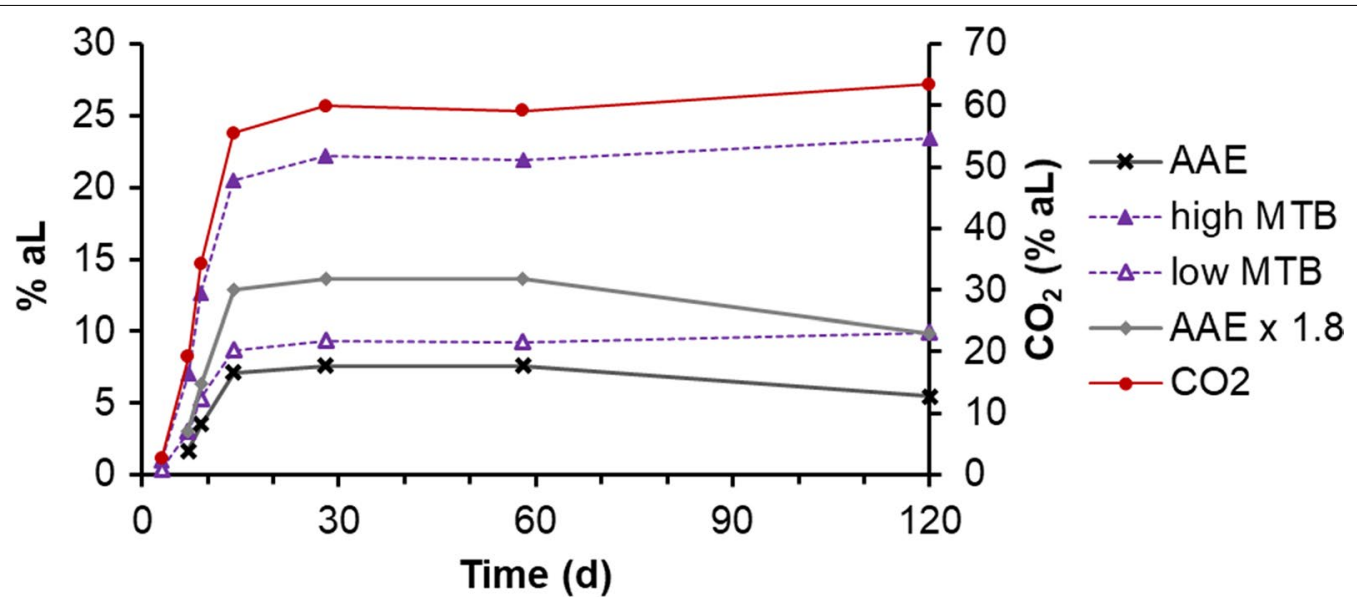

Fig. 4 Measured \%aL in cleaned-up column extract (AAE "amino acid extract", black line and crosses) and $\mathrm{CO}_{2}$ (\%aL right axis, red circles and red dotted line), AAE times factor $b=1.8$ (grey line and triangles), in comparison to low (dotted violet line and empty violet triangles) and high calculated MTB-bioNER (filled violet triangles and dashed violet line) for substance no. 4 at seven consecutive sampling times $(3,7,9,14,28,58$, 120 days). Means of replicate samples are shown $(n=2)$ 
is formed with no storage of intermediates. In addition, MTB assumes that either energy or carbon is limiting the yield, and slightly modified the method allows also to consider nutrient limitation, e.g., by phosphorous or nitrogen [16]. Growth yield estimates can be performed with oxygen as terminal electron acceptor (aerobic degradation), but also with nitrate or sulfate (anaerobic degradation) [22]. Due to thermodynamic reasons, the yield is highest with oxygen and lowest with sulfate. Hence, the method is rather flexible and can be adapted to a variety of redox couples and environmental conditions, if they are described sufficiently.

The MTB growth yield estimation is less sensitive to uncertain $\Delta G$ input data than other yield estimation methods [22], nonetheless uncertainties of the input values, e.g., the $\Delta G$ values and the reaction schemes, can lead to variations in the calculated yield. We can show this for the example of bromoxynil. For the yield given in Table 3, the underlying reaction equation was assumed to be:

$$
\mathrm{C}_{7} \mathrm{H}_{3} \mathrm{Br}_{2} \mathrm{NO}+6 \mathrm{O}_{2}+\mathrm{OH}^{-} \rightarrow 7 \mathrm{CO}_{2}+2 \mathrm{Br}^{-}+\mathrm{NH}_{4}^{+}
$$

with the Gibbs energy of the reaction (standard conditions, units $\mathrm{kJ} / \mathrm{mol}$, [18]).

$$
\begin{aligned}
\Delta \mathrm{G}_{r}^{0}= & {[7(-386)+2(-105.19)+(-79.4)] } \\
& -[+147.8+0+(-157.2)] \mathrm{kJ} / \mathrm{mol} \\
= & -2982.6 \mathrm{~kJ} / \mathrm{mol}
\end{aligned}
$$

The yield of bromoxynil is then $0.164 \mathrm{gC} / \mathrm{gC}$ using the tabulated $\Delta G$-values in Diekert (1997) [17], $0.166 \mathrm{gC} / \mathrm{gC}$ with $\Delta G$-values derived from Thauer et al. (1977) [23] or $0.174 \mathrm{gC} / \mathrm{gC}$ with $\Delta G$-values from Alberty (2003) [47], corresponding to 0.09 to $0.10 \mathrm{~g}$ biomass per g bromoxynil (showing that small differences in $\Delta G$ have little influence on the calculated result).

Under reductive conditions, a dehalogenation of bromoxynil may occur, leading to the metabolite 4-hydroxybenzonitrile (www.envipath.org) by replacing the bromine atoms by hydrogen. This may increase the energy available for microbes upon mineralization and the estimated yield increases to $0.26 \mathrm{gC} / \mathrm{gC}$ ( $\Delta \mathrm{G}$-values from [18]). A partly anaerobic test environment can thus change the microbial yield quite significantly and hence also the formation of bioNER. This may explain the large variation in measured amounts of the bioNER of bromoxynil (Table 3).

Known limitations of the MTB yield assessment. In degradation studies, microorganisms may not use the full potential of a substrate because the enzymes are not adapted to a degradation pathway or not present at all, or if an appropriate electron acceptor is not present in sufficient concentrations; this can lead to accumulation of intermediate metabolites and lower yields. In mixed cultures (natural inocula) and environmental samples from simulation tests [2-4], growth of multiple strains on multiple substrates is likely in particular in soils, sediments, and sludges. A selection process among the microorganisms of a degrader population selecting for the most efficiently growing strain (which have the highest possible yield, i.e., close to or at the theoretical yields) will take place more likely if the substrate is the only growth substrate and carbon source. This again is much more likely to be the case at higher initial concentrations and MTB is developed particularly for these metabolic conditions. The consumption of other substrates contributes to the metabolism of the degrader organisms and thus the bioNER values may even be lower than the low MTB values.

In addition, with current analytical techniques, stable isotope $\left({ }^{13} \mathrm{C}\right)$ labeling requires higher initial concentrations than radio-labeling $\left({ }^{14} \mathrm{C}\right)$. Hence, non-adapted microbial communities with lower yield (and higher $\mathrm{CO}_{2}$-formation) are more likely for tests with ${ }^{14} \mathrm{C}$ label, and in this case the MTB assessment may overestimate bioNER formation.

In case of incomplete metabolism with accumulation of metabolic products, the yield assessment can still be made, if these products are known and quantified [16]. However, yield estimates by MTB are not defined and may not be valid for non-growth supporting co-metabolism [48], for the use of parts of the molecule as biomass building block, and for use of the target substrate as electron acceptor. In these cases, the substrate is depleted, but microorganisms do not or only slowly grow on it, and also $\mathrm{CO}_{2}$ development is none or small.

Flaws of the MTB and bioNER assessment. From the assumptions and limitations of the MTB method follows that deviations from the predicted range of bioNER may occur:

- if the degradation is incomplete, i.e., transformation/ degradation products accumulate and are not considered in the calculation or are used directly as building blocks for biomass formation.

- if the degradation is (partly or fully) anaerobic, and methane $\left(\mathrm{CH}_{4}\right)$ is formed instead of $\mathrm{CO}_{2}$; for nitrate and sulfate as the electron acceptors the yield is lower due to lower Gibbs energy of the reaction [22].

- if there is significant storage of carbon within the cell, e.g., in form of carbohydrates, poly-ß-hydroxy acids, or polyphosphates. In this case, the release of $\mathrm{CO}_{2}$ by mineralization is delayed. The equations for the bioNER assume, however, immediate 
release of $\mathrm{CO}_{2}$. In consequence, the true bioNER may be higher than predicted from released $\mathrm{CO}_{2}$ and potential yields.

- if the natural inoculum does not contain microorganisms with enzymes for efficient and complete mineralization of the substrate, the resulting experimental data may differ from the theoretical result.

- if the substrate is applied in concentrations toxic to microorganisms, or inhibiting enzyme reactions $[20,49]$, the actual yield can be lower than expected by MTB. This is more likely if ${ }^{13} \mathrm{C}$-label is used because this requires higher initial concentrations.

In degradation experiments, any of these limitations may occur, but they may not always be noticed, and it is difficult to prove their occurrence. Therefore, careful assessment of the interfering processes is needed and these limitations may explain the large deviations between estimated growth yield or bioNER and experimentally determined values.

\section{Uncertainties in the experimental data}

The correlation between estimated MTB-bioNER and measured proxies for bioNER such as tAA or AAE is significant, but in several cases (in particular for hardly degradable compounds) there are large differences between estimated and experimental bioNER, in average about $5 \%$ aL (low MTB) to $14 \%$ aL (high MTB). It is not possible to define the source of this disagreement yet. However, given the high variance and the difficulties of the experimental determination in different soils, this disagreement, presumably, partly origins from the (im-)precision of the measured data. From the assumptions and limitations underlying the MTB method, a number of reasons could be identified for deviations from experimental results, although there is no proof that any of these short-comings did happen. Considering the large variations of NER formation of chemicals in different soils and under different conditions [5], the difference of measured and calculated bioNER amounts is relatively minor in most cases.

Table 3 also lists four data sets where bioNER was not determined via protein mass but by alternative methods. The result for bisphenol A [27] is below the estimated bioNER range. The results for isoproturon [28] and MCPA [25] was within the predicted range, and the result for pendimethalin [26] is above. The reason for the latter may be that the given number is for the sum of experimentally determined NER II and III.

\section{Conclusions}

Productive microbial biodegradation of labeled test chemicals leads to the incorporation of the label in the microbial mass. As a result, biogenic NER, which are not harmful and without environmental relevance, is formed. The amount of bioNER formed can be estimated using the MTB approach. It needs minimum input data, all of them readily available without additional experimental effort. The MTB approach can thus be employed to discriminate between potentially remobilizable (thus harmful) NER, and irreversibly bound (not harmful) NER without additional experimental efforts. This is very useful in the context of the new paradigm of the European Chemicals Agency, which suggests to consider unidentified NER as equivalent to parent substance in the $\mathrm{P}$ assessment.

The particular advantage of the MTB approach is that it provides a tool to assess the actual biomass formation by relating it to the microbial activity via the $\mathrm{CO}_{2}$ formed. Predicted growth yields vary much less than experimental $\mathrm{CO}_{2}$, thus, the variance in bioNER estimations can mostly be contributed to the variance in $\mathrm{CO}_{2}$ formation $\left(\mathrm{CO}_{2}\right.$ alone is a good predictor for biological activity, and thus also for bioNER formation, as can be seen from the correlation to tAA). Hence, inconsistent or unreliable measurements can be identified by comparison to $\mathrm{CO}_{2}$ determined. Unreliable results may also be detected by degradation experiments under sterile conditions, and by comparison to MTB results.

The comparison with experimental data was faced with difficulties. There is currently no established experimental standard procedure for the determination of NER and bioNER, and a variety of methods have been reported in scientific literature, accompanied by a large variety of experimental conditions, such as test duration, soil type, concentrations, etc.. Experimental data showed considerable scatter for those cases, where the bioNER formation of the same compound was studied in replicates or in different soils. Some observed deviations between experiment and calculation can thus be contributed to shortcomings of the experimental bioNER quantification. Further harmonization of experimental methods and additional studies are thus necessary to decrease the variance of the experimental outcome and disagreement between calculated and measured bioNER. We found a significant correlation between predicted and measured results, which means that the MTB-bioNER usually gives high results when the measured bioNER is high. However, the estimated bioNER values in average differed only between $5 \% \mathrm{aL}$ (low MTB) to $14 \% \mathrm{aL}$ (high MTB) from the measured tAA. If the tAA-values are multiplied with a factor to consider the difference between amino 
acid and biomass, the difference is reduced. However, that factor is not a constant but may vary with experimental set-up and duration and ranges from 1.8 to 1.0. Factor 1.8 (55\% protein content in biomass) seems to be a reasonable default value.

The particular advantage of the MTB approach is that it provides a tool to assess the biomass formation by relating it to the microbial activity via the $\mathrm{CO}_{2}$ formed. As the approach relies on the measured $\mathrm{CO}_{2}$ released, it is not affected by the degradability of the compound, e.g., hardly degradable compounds do not produce $\mathrm{CO}_{2}$. It can thus indicate those studies where the NER is formed partly or mostly from bioNER, and where additional experimental efforts may lead to lower half-lives in the $\mathrm{P}$ assessment.

\section{Acknowledgements}

Daniela Claßen for sending additional data to her paper Claßen et al. [23]. This study was supported by the German Umweltbundesamt Project FKZ 3718654070 Berücksichtigung nicht-extrahierbarer Rückstände (NER) in der PBT-Bewertung (Consideration of non-extractable residues (NER) in the PBT assessment, 2018-2020). We thank in particular Ulrich Jöhnke, Astrid Wiemann, Daniela Claßen, Jana Schmidt, Gunther Speichert and Anna Pissarello from UBA. Andreas Libonati Brock was partly supported by a research grant (35802) from VILLUM FONDEN.

\section{Authors' contributions}

$\mathrm{ST}, \mathrm{ALB}$, and MK designed the study and wrote the manuscript. AS provided additional comments and expertise. DH provided many of the data presented. AS and DH commented the manuscript. All authors read and approved the final manuscript.

\section{Funding}

Open Access funding enabled and organized by Projekt DEAL. All funding sources were declared.

\section{Availability of data and materials}

Not applicable.

\section{Declarations}

Ethics approval and consent to participate

Not applicable.

\section{Consent for publication}

Not applicable.

\section{Competing interests}

The authors declare that they do not have any competing interests.

\begin{abstract}
Author details
'Department Environmental Biotechnology, Helmholtz Centre for Environmental Research, UFZ, 04318 Leipzig, Germany. ${ }^{2}$ Department of Environmental Engineering, Technical University of Denmark, 2800 Kongens Lyngby, Denmark. Institute for Environmental Research, RWTH Aachen University, 52074 Aachen, Germany. ${ }^{4}$ Fraunhofer Institute for Molecular Biology and Applied Ecology IME, 57392 Schmallenberg, Germany.
\end{abstract}

Received: 19 November 2021 Accepted: 21 January 2022 Published online: 16 February 2022

\section{References}

1. Cousins IT, Ng CA, Wang ZY, Scheringer M (2019) Why is high persistence alone a major cause of concern? Environ Sci Processes Impacts 21(5):781-792. https://doi.org/10.1039/c8em00515j

2. EC European Commission (2006) Regulation (EC) No 1907/2006 of the European Parliament and the Council of 18 December 2006 concerning Registration, Evaluation, Authorisation and Restriction of Chemicals (REACH). Official Journal of the European Union; 2006, L 136

3. OECD (2002a) Test No. 307: aerobic and anaerobic transformation in soil, OECD Guidelines for the Testing of Chemicals, Section 3, OECD Publishing, Paris, https://doi.org/10.1787/9789264070509-en

4. OECD (2002b) Test No. 308: aerobic and anaerobic transformation in aquatic sediment systems, OECD Guidelines for the Testing of Chemicals, Section 3, OECD Publishing, Paris, https://doi.org/10.1787/9789264070 523 -en

5. OECD (2004) Test No. 309: aerobic mineralisation in surface water-simulation biodegradation test, OECD Guidelines for the Testing of Chemicals, Section 3, OECD Publishing, Paris, https://doi.org/10.1787/9789264070 547-en

6. Barriuso E, Benoit P, Dubus IG (2008) Formation of pesticide nonextractable (bound) residues in soil: magnitude, controlling factors and reversibility. Environ Sci Technol 42:1845-1854

7. ECHA European Chemicals Agency (2019) Options to address nonextractable residues in regulatory persistence assessment. Note released 10th of June 2019, ECHA website: https://echa.europa.eu/documents/ 10162/13632/bg_note_addressing_non-extractable_residues.pdf/e88d4 fc6-a125-efb4-8278-d58b31a5d342. Accessed on 4 Nov 2021.

8. Harmsen J, Hennecke D, Hund-Rinke K, Lahr J, Deneer J (2017) Advances in the development of procedures to establish the toxicity of nonextractable residues (NER) in soil. SETAC Europe 27th Annual Meeting 2017

9. Kästner M, Nowak KM, Miltner A, Trapp S, Schäffer A (2014) Classification and modelling of non-extractable residue (NER) formation of xenobiotics in soil-a synthesis. Crit Rev Environ Sci Technol 44(19):1-65

10. Kästner M, Trapp S, Schäffer A (2018) Consultancy Services to Support ECHA in Improving the Interpretation of Non-Extractable Residues (NER) in Degradation Assessment. Discussion Paper-Final Report. Edited by the European Chemical Agency ECHA (June 2018). www.echa.europa.eu/ publications/technical-scientific-reports

11. Schäffer A, Kästner M, Trapp S (2018) A unified approach for including non-extractable residues (NER) of chemicals and pesticides in the assessment of persistence. Environ Sci Eur 30:51. https://doi.org/10.1186/ s12302-018-0181-x

12. ECHA European Chemicals Agency (2017a) Guidance on information requirements and chemical safety assessment, Chapter R.7b: Endpoint specific guidance, version 4.0

13. ECHA European Chemicals Agency (2017b) Guidance on information requirements and chemical safety assessment, Chapter R.7c: Endpoint specific guidance, version 3.0

14. ECHA European Chemicals Agency (2017c) Guidance on information requirements and chemical safety assessment, Chapter R.11: Endpoint specific guidance (PBT/VPvB assessment), version 3.0

15. Trapp S, Brock AL, Nowak K, Kästner M (2018) Prediction of the formation of biogenic nonextractable residues during degradation of environmental chemicals from biomass yields. Environ Sci Technol 52:663-672. https://doi.org/10.1021/acs.est.7b04275

16. Brock AL, Rein A, Polesel F, Nowak K, Kästner M, Trapp S (2019) Understanding the mechanisms of incomplete biodegradation of glyphosate: utilization as nutrient source, formation of AMPA and biogenic NER. Environ Sci Technol 53(10):5838-5847. https://doi.org/10.1021/acs.est. 9b01259

17. Heijnen JJ (1991) A new thermodynamically based correlation of chemotrophic biomass yields. Antonie Van Leeuwenhoek 60(3-4):235-256. https://doi.org/10.1007/BF00430368

18. Diekert G (1997) Grundmechanismen des Stoffwechsels und der Energiegewinnung. In: Ottow JCG, Bidlingmaier W (eds) Umweltbiotechnologie. Fischer, Stuttgart, Germany, pp 1-38

19. VanBriesen JM (2002) Evaluation of methods to predict bacterial yield using thermodynamics. Biodegradation 13(3):171-190 
20. McCarty PL (2007) Thermodynamic electron equivalents model for bacterial yield prediction: Modifications and comparative evaluations. Biotechnol Bioeng 97(2):377-388

21. Xiao J, VanBriesen JM (2008) Expanded thermodynamic true yield prediction model: adjustments and limitations. Biodegradation 19(1):99-127

22. Brock AL, Kästner M, Trapp S (2017) Microbial growth yield estimates from thermodynamics and its importance for degradation of pesticides and formation of biogenic non-extractable residues. SAR/QSAR 28(8):629650. https://doi.org/10.1080/1062936X.2017.1365762

23. Thauer RK, Jungermann K, Decker K (1977) Energy conservation in chemotrophic anaerobic bacteria. Bacteriol Rev 41(1):100-180

24. Miltner A, Bombach P, Schmidt-Brücken B, Kästner M (2012) SOM genesis: microbial biomass as a significant source. Biogeochemistry 111(1-3):41-55

25. Nowak KM, Miltner A, Poll C, Kandeler E, Streck T, Pagel H (2020) Plant litter enhances degradation of the herbicide MCPA and increases formation of biogenic non-extractable residues in soil. Environ Int 142:105867. https://doi.org/10.1016/j.envint.2020.105867

26. Luks A-K, Zegarski T, Nowak KM, Miltner A, Kästner M, Matthies M, Schmidt B, Schäffer A (2021) Fate of pendimethalin in soil and characterization of non-extractable residues (NER). Sci Tot Environ 753:141870. https://doi.org/10.1016/j.scitotenv.2020.141870

27. Cao S, Wang S, Zhao Y, Wang L, Ma Y, Schaeffer A, Ji R (2020) Fate of bisphenol S (BPS) and characterization of non-extractable residues in soil: insights into persistence of BPS. Environ Int 143:105908. https://doi.org/ 10.1016/j.envint.2020.105908

28. Zhu X, Schroll R, Dörfler U, Chen B (2018) Inoculation of soil with an Isoproturon degrading microbial community reduced the pool of "real nonextractable" isoproturon residues. Ecotoxicol Environ Saf 149:182-189. https://doi.org/10.1016/j.ecoenv.2017.11.037

29. Hennecke D, Schäffer A, Kästner M, Trapp S (2018) Berücksichtigung nicht-extrahierbarer Rückstände (NER) in der PBT-Bewertung (Consideration of non-extractable residues (NER) in the PBT assessment, Umweltbundesamt Project FKZ 371865407 02018-2020), Fraunhofer IMT (Schmallenberg, Germany)

30. Nowak KM, Miltner A, Gehre M, Schäffer A, Kästner M (2011) Formation and fate of bound residues from microbial biomass during 2,4-D degradation in soil. Environ Sci Technol 45:999-1006

31. Girardi C, Nowak KM, Carranza-Diaz O, Lewkow B, Miltner A, Gehre M, Schäffer A, Kästner M (2013) Microbial degradation of the pharmaceutical ibuprofen and the herbicide 2,4-D in water and soil-use and limits of data obtained from aqueous systems for predicting their fate in soil. Sci Total Environ 444:32-42

32. Wang S, Seiwert B, Kästner M, Miltner A, Schäffer A, Reemtsma T, Yang Q, Nowak KM (2016) (Bio)degradation of glyphosate in water-sediment microcosms - a stable isotope co-labeling approach. Water Res 99:91-100. https://doi.org/10.1016/j.watres.2016.04.041

33. Claßen D, Siedt M, Nguyen KT, Ackermann J, Schaeffer A (2019) Formation, classification and identification of non-extractable residues of ${ }^{14} \mathrm{C}$-labelled ionic compounds in soil. Chemosphere 232:164-170. https:// doi.org/10.1016/j.chemosphere.2019.05.038

34. Nowak KM, Telscher M, Seidel E, Miltner A (2018) Unraveling microbial turnover and non-extractable residues of bromoxynil in soil microcosms with 13C-isotope probing. Environ Pollut 242:769-777. https://doi.org/10. 1016/j.envpol.2018.07.049

35. Poßberg C, Schmidt B, Nowak K, Telscher M, Lagojda A, Schaeffer A (2016) Quantitative identification of biogenic nonextractable pesticide residues in soil by ${ }^{14} \mathrm{C}$-analysis. Environ Sci Technol 50:6415-6422. https://doi.org/ 10.1021/acs.est.6b00689

36. Wang S, Miltner A, Nowak KM (2017) Identification of degradation routes of metamitron in soil microcosms using 13C-isotope labeling. Environ Pollut 220:927-935

37. Non-extractable residues in persistence assessment. https://www.umwel tbundesamt.de/en/topics/chemicals/reach-what-is-it/non-extractableresidues-in-persistence-assessment. Accessed 4 Nov 2021

38. Junge T, Meyer KC, Ciecielski K, Adams A, Schäffer A, Schmidt B (2011) Characterization of non-extractable 14C-and 13C-sulfadiazine residues in soil including simultaneous amendment of pig manure. J Environ Sci Health Part B Pest Food Contam Agric Wastes 46(2):137-149. https://doi. org/10.1080/03601234.2011.535371
39. Chen J, Jiang X, Tong T, Miao S, Huang J, Xie S (2019) Sulfadiazine degradation in soils: dynamics, functional gene, antibiotic resistance genes and microbial community. Sci Total Environ 691:1072-1081. https://doi.org/ 10.1016/j.scitotenv.2019.07.230

40. Flamholz A, Noor E, Bar-Even A, Milo R (2012) eQuilibrator-the biochemical thermodynamics calculator Nucleic Acids Res 40:D770-5 (http://equil ibrator.weizmann.ac.il)

41. Madigan MT, Martinko JM, Bender KS, Buckley DH, Stahl DA (2014) Brock biology of microorganisms, 14th edn. Pearson Inc., Boston, USA

42. Adam IKU, Rein A, Miltner A, Fulgêncio ACD, Trapp S, Kästner M (2014) Experimental results and integrated modeling of bacterial growth on an insoluble hydrophobic substrate (phenanthrene). Environ Sci Technol 48(15):8717-8726

43. Kindler R, Miltner A, Thullner M, Richnow HH, Kästner M (2009) Fate of bacterial biomass derived fatty acids in soil and their contribution to soil organic matter. Org Geochem 40(1):29-37

44. Egli T (2010) How to live at very low substrate concentration. Water Res 44:4826-4837

45. Helbling DE, Hammes F, Egli T, Kohler H-PE (2014) Kinetics and yields of pesticide biodegradation at low substrate concentrations and under conditions restricting assimilable organic carbon. Appl Environ Microb 80(4):1306-1313

46. Kovarova-Kovar K, Egli T (1998) Growth kinetics of suspended microbial cells: from single-substrate-controlled growth to mixed-substrate kinetics. Microbiol Mol Biol Rev 62(3):646-666

47. Alberty RA (2003) Thermodynamics of biochemical reactions. Wiley, New York. https://onlinelibrary.wiley.com/doi/book/10.1002/0471332607

48. Criddle CS (1993) The kinetics of cometabolism. Biotech Bioeng 41(11):1048-1056. https://doi.org/10.1002/bit.260411107

49. Rein A, Adam IKU, Miltner A, Brumme K, Kästner M, Trapp S (2016) Impact of bacterial activity on turnover of insoluble hydrophobic substrates (phenanthrene and pyrene)_model simulations for prediction of bioremediation success. J Hazard Mater 306:105-114. https://doi.org/10. 1016/j.jhazmat.2015.12.005

\section{Publisher's Note}

Springer Nature remains neutral with regard to jurisdictional claims in published maps and institutional affiliations.

\section{Submit your manuscript to a SpringerOpen ${ }^{\circ}$ journal and benefit from:}

- Convenient online submission

- Rigorous peer review

- Open access: articles freely available online

- High visibility within the field

Retaining the copyright to your article

Submit your next manuscript at $\boldsymbol{\nabla}$ springeropen.com 